Molecules 2005, 10, 1197-1208

molecules

ISSN 1420-3049

http://www.mdpi.org

\title{
Relationship Between Physicochemical Properties and Herbicidal Activity of 1,2,5-Oxadiazole $\mathrm{N}$-Oxide Derivatives
}

Luciana A. Fernandez ${ }^{1}$, Marisa R. Santo ${ }^{1}$, Mario Reta ${ }^{1}$, Liliana Giacomelli ${ }^{1}$, Rosa Cattana ${ }^{1}$, Juana J. Silber ${ }^{1, *}$, Mariela Risso ${ }^{2}$, Hugo Cerecetto ${ }^{2}$, Mercedes Gonzalez ${ }^{2}$ and Claudio OleaAzar $^{3}$

${ }^{1}$ Departamento de Química. Universidad Nacional de Río Cuarto. Agencia Postal Nro 3. 5800. Río Cuarto, Argentina.

2 Departamento de Química Orgánica. Facultad de Química - Facultad de Ciencias. Universidad de la República. CC 1157. 11800. Montevideo, Uruguay.

3 Departamento de Química Inorgánica y Analítica. Facultad de Ciencias Químicas y Farmacéuticas. Universidad de Chile, Chile.

* Author to whom correspondence should be addressed; E-mail jsilber@exa.unrc.edu.ar

Received: 2 December 2004; in revised form 8 July 2005 / Accepted: 9 July 2005 / Published: 30 September 2005

\begin{abstract}
The relationship between the herbicidal activity of a number of novel 1,2,5oxadiazole $\mathrm{N}$-oxides and some physicochemical properties potentially related with this bioactivity, such as polarity, molecular volume, proton acceptor ability, lipophilicity, and reduction potential were studied. The semiempirical molecular orbital method AM1 was used to calculate theoretical descriptors such as dipolar moment, molecular volume, Mulliken's charge and the octanol/water partition coefficients $\left(\log \mathrm{P}_{\mathrm{o} / \mathrm{w})}\right.$. The values of the reduction potentials $\left(E_{r}\right)$ were obtained by cyclic voltammetry. In addition, the retention factors ( $\log \mathrm{k}_{\mathrm{w}}{ }_{\mathrm{w}}$ ) on a reversed-phase high-performance liquid chromatography (RP-HPLC) column in pure aqueous mobile phases were measured for several $\mathrm{N}$-oxide derivatives. The $\log \mathrm{k}^{\prime}{ }_{\mathrm{w}}$ values show good correlation with the calculated values of log $\mathrm{P}_{\mathrm{o} / \mathrm{w}}$, showing that the chromatographic parameter can be used as lipophilicity descriptor for these compounds. The multiple regression analysis between the descriptors for the $\mathrm{N}$ oxide derivatives and the herbicide activity indicate that the variance in the biological activity can be explained by changes in the lipophilicity and in the reduction potential.
\end{abstract}

Keywords: 1,2,5-Oxadiazole $N$-oxide derivatives; herbicides; lipophilicity 


\section{Introduction}

The bio-response of a compound can be the result of several types of interactions between the bioactive compound and the receptor, such as hydrophobic and electrostatic forces, hydrogen bonding and electron donor acceptor complex [1]. These interactions are closely related to physicochemical and structural properties of its component molecules. Therefore it is possible the prediction or explanation of the biological behaviour of molecules from their physicochemical properties. The basic assumption underlying this field of research called quantitative structure-activity relationships (QSAR) is that the structure of a molecule determines its performance [2]. This paradigm can be expressed by $\mathrm{P}=\mathrm{f}(\mathrm{S})$ [3], where $\mathrm{P}$ is any physical, agrochemical, biomedical, toxicological or environmental activity of interest and S may represent either an empirical property of the total molecular structure, a relevant substructure fragment or a theoretical structural descriptor (or a set of descriptors) quantifying some aspects of molecular structure.

Drug lipophilicity is a physicochemical property very useful for bioactivity predictions $[4,5]$. Transport and distribution processes within biological systems are to a large extent controlled by lipophilicity of the system components. The highly hydrophobic interior of a bilayer membrane enables or facilitates the passage of lipophilic substances and prevents the free diffusion of polar molecules except water in and out of cells [6].

Lipophilicity is usually measured by determining the equilibrium concentration of the compound in two immiscible polar/non polar liquids and expressed as the logarithm of the partition coefficient. The octanol-water partition coefficient $\left(\log \mathrm{P}_{\mathrm{o} / \mathrm{w}}\right)$ is the parameter most widely used to measure hydrophobicity [7] because it has been shown that this partition system is a good model for many biological processes [6]. However, experimental log Po/w measurements are time-consuming and are limited to a certain range, e.g. $-3<\log \mathrm{Po} / \mathrm{w}<3$ [8]. It is possible to obtain $\log$ Po/w values from fragmental contributions of the different atoms using computational calculations. [9]. Chromatographic methods have been also been used successfully to assess lipophilicity of organic compounds [10, 11]. Thus, the retention factor in RP-HPLC with pure aqueous mobile phases ( $\log k^{\prime}{ }_{w}$ ) is commonly used as a lipophilic descriptor [8, 12]. Several advantages are attributed to $\log \mathrm{k}_{\mathrm{w}}{ }_{\mathrm{w}}$. A priori, it reflects polar/no polar partitioning in a manner similar to shake-flask measurements and it is dependent on the solute structure and polar functionalities. However, it is difficult to measure directly, because of the prohibitively long retention times of organic solutes in pure water as mobile phase.

On the other hand, electrostatic properties play a crucial role in the receptor-bioactive compound recognition process. A great number of electrostatic descriptors have been described. Basically, semiempirical and $a b$ initio methods have to be distinguished in the electrostatic descriptors determinations. The most frequently used descriptor includes the highest occupied and lower unoccupied molecular orbital, frontier orbital electron densities, Mulliken's population charge distribution and dipole moments $[13,14]$.

In this sense, some electrostatic properties i.e. electron affinity, LUMO's and HOMO's energies can be related to experimental properties such as redox potentials. Furthermore, the latter is known to be related to bio-reduction or bio-oxidation processes of bioactive compounds [15]. The electrochemical response can be experimentally studied, i.e. by polarographic or by cyclic voltammetry techniques [16]. 
In this work we studied the relationship between the phytotoxic activity of a number of novel 1,2,5-oxadiazole $\mathrm{N}$-oxide with a variegated set of substituents (Scheme I) and some physicochemical properties potentially related with such activity, such as lipophilicity descriptors, dipolar moment, molecular volume, hydrogen bond acceptor ability and reduction potential. Previous studies [17] have shown that these 1,2,5-oxadiazole $N$-oxide derivatives exhibit moderate to good herbicidal activity against Triticum aestivum, indicating that the $N$-oxide moiety could be participating in the phytophore, since in absence of it, a sharp loss of activity was observed (derivative 19, Scheme 1).

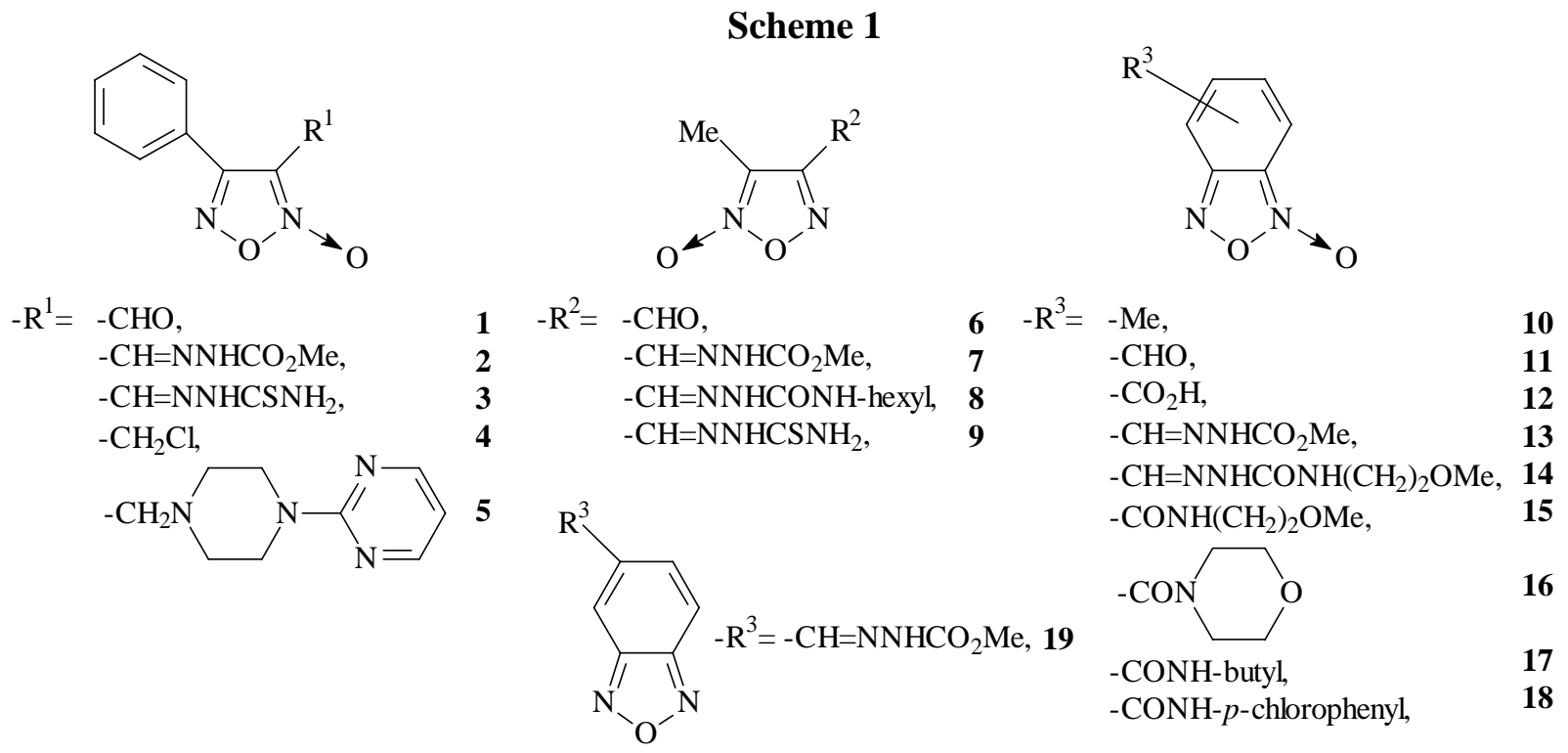

\section{Results and Discussion}

The following parameters have used: the chromatographic $\log \mathrm{k}_{\mathrm{w}}{ }_{\mathrm{w}}$ and the calculated $\log \mathrm{P}_{\mathrm{o} / \mathrm{w}}$ parameters for lipophilicity; the calculated molecular volume, V, as a geometrical (steric) descriptor; charge density, $\mathrm{q}_{\mathrm{o}}$, on the $\mathrm{O}$ atom of the $\mathrm{N} \rightarrow \mathrm{O}$ group to estimate the hydrogen-bond acceptor ability $[18,19]$; reduction potential, $E_{r}$, and the LUMO's energy as accounting for electron acceptor interactions or electronic affinity; and the calculated dipolar moment, $\mu$ as an electrostatic descriptor. All the measured and calculated parameters for those compounds are reported in Table 1. In the following sections the details the methodology used to obtain this descriptors is described.

Lipophilicity determinations using an octadecylsilane (ODS) RP-HPLC column.

Thus, $\log \mathrm{k}_{\mathrm{w}}$ is most often estimated by extrapolating a linear plot of log $\mathrm{k}^{\prime}$ vs. volume percent of organic modifier $(\Phi)$ to $100 \%$ water [20], equation (1):

$$
\log k^{\prime}=\log k_{w}^{\prime}-S \Phi
$$


Table 1: Herbicidal activity indexes for the $N$-oxide derivatives and some of their experimental and calculated descriptors.

\begin{tabular}{|c|c|c|c|c|c|c|c|c|c|}
\hline Compound $^{\mathrm{a}}$ & $\mathbf{R} \mathbf{w}^{\mathbf{b}}$ & $A w^{\mathbf{b}}$ & $\mathbf{L f f}^{\mathbf{b}}$ & $E_{r}{ }^{c}$ & $\log k_{w}^{\prime}{ }_{w}^{d}$ & $\log P_{0 / w}{ }^{e}$ & $V^{f}$ & $\mu^{\mathrm{f}}$ & $\mathbf{q}_{0}^{\mathrm{N} \rightarrow \mathrm{O}, \mathrm{f}}$ \\
\hline 1 & -19 & 18 & -4 & -1.20 & - & 4.95 & 534 & 2.06 & 0.238 \\
\hline 2 & -48 & 16 & -22 & -1.19 & 3.34 & 3.76 & 742 & 4.52 & 0.304 \\
\hline 3 & -57 & 8 & -30 & -1.03 & 3.24 & 3.69 & 723 & 3.94 & 0.304 \\
\hline 4 & -15 & -7 & -4 & -0.99 & 4.24 & 4.25 & 573 & 4.7 & 0.292 \\
\hline 5 & 0 & 0 & 0 & -1.22 & - & 4.03 & 943 & 4.07 & 0.298 \\
\hline 6 & -11 & -5 & -5 & -1.62 & 0.22 & 1.88 & 375 & 2.17 & 0.302 \\
\hline 7 & 97 & -50 & -50 & -2.08 & 1.47 & 2.33 & 575 & 5.67 & 0.312 \\
\hline 8 & -75 & -85 & -50 & -1.59 & 4.39 & 4.01 & 859 & 7.91 & 0.316 \\
\hline 9 & -86 & -95 & -- & -- & 1.18 & 2.25 & 568 & 1.38 & 0.309 \\
\hline 10 & -69 & -58 & -58 & -2.00 & 2.18 & 3.42 & 451 & 4.76 & 0.274 \\
\hline 11 & -4 & -5 & -30 & -0.93 & 2.40 & 4.27 & 454 & 1.39 & 0.274 \\
\hline 12 & -23 & -9 & -16 & -- & - & 2.66 & 475 & 2.02 & 0.280 \\
\hline 13 & -17 & 13 & -6 & -1.17 & 2.02 & 3.08 & 660 & 5.20 & 0.276 \\
\hline 14 & -- & -- & -- & -1.10 & 2.31 & 2.60 & 809 & 8.8 & 0.278 \\
\hline 15 & -11 & -2 & -23 & -1.54 & 1.46 & 2.20 & 685 & 3.59 & 0.281 \\
\hline 16 & -57 & -52 & -55 & -2.06 & 1.27 & 4.89 & 675 & 2.59 & 0.278 \\
\hline 17 & -51 & -66 & -71 & -1.54 & 2.74 & 5.75 & 706 & 4.93 & 0.269 \\
\hline 18 & -91 & -73 & -50 & -1.43 & - & 6.74 & 751 & 3.65 & 0.265 \\
\hline 19 & 10 & 20 & 35 & -- & 2.21 & 1.80 & 635 & 3.36 & C \\
\hline
\end{tabular}

a Compounds 1-9 oxadiazole derivatives, 10-19 benzooxadiazole derivatives. ${ }^{\mathrm{b}}$ Pre-emergent herbicidal activity indexes(change of the corresponding parameters respect to untreated reference, (-) denote decreasing parameters, $(+)$ denote increasing parameters : radicular weight (rw), aerial weight (aw), and length of the leaf (lfl); ${ }^{c}$ Reduction Potential (V, vs Calomel saturated electrode); ${ }^{d}$ The logarithm of the chromatographic retention factor extrapolated to pure water; ${ }^{e}$ Computationally calculated parameters: $\mathrm{P}_{\mathrm{o} / \mathrm{w}}$ is the octanol-water partition coefficient, $\mathrm{V}^{\mathrm{f}}$ is the molecular volume, $\mu$ the dipolar moment and $\mathrm{q}_{\mathrm{o}}^{\mathrm{N} \rightarrow \mathrm{O}}$ the atomic charge on the $\mathrm{O}$ atom of $\mathrm{N}$-oxide moiety respectively;

Kaliszan [21] discussed the shortcomings of using $\log \mathrm{k}_{\mathrm{w}}{ }_{\mathrm{w}}$ as a lipophilic descriptor, that includes the actual dependence of log k' with $\Phi$ (linear or quadratic) and, in some instances, with the organic modifier which results in a questionable physical meaning for $\log \mathrm{k}^{\prime}{ }_{\mathrm{w}}$. Neither the $\log \mathrm{P}_{\mathrm{o} / \mathrm{w}}$ nor any of the chromatographic hydrophobicity scales is unique, pharmacologically distinguished [22]. In light of this, we believe that the best chromatographic or partitioning system for a particular case under study is that which better mimics the molecular interactions between the drug and the biological system, but up to the present, finding that scale is an empirical process.

An alternative method to estimate the $\log \mathrm{k}_{\mathrm{w}}^{\prime}$ values uses the $\mathrm{E}_{\mathrm{T}}(30)$ solvatochromic scale, an empirical measure of solvent polarity (equation 2): 


$$
\log \mathrm{k}_{\mathrm{w}}^{\prime}=\mathrm{a}-\mathrm{b} \mathrm{E}_{\mathrm{T}}(30)
$$

Here $\log \mathrm{k}_{\mathrm{w}}{ }_{\mathrm{w}}$ is obtained by replacing the $\mathrm{E}_{\mathrm{T}}(30)$ value of pure water in equation 2 and the $\mathrm{a}$ and $\mathrm{b}$ coefficients are obtained by linear extrapolation of $\log \mathrm{k}_{\mathrm{w}}{ }_{\mathrm{v}} \mathrm{vs} \mathrm{E}_{\mathrm{T}}(30)$ values for the different mobile phases employed [22]. The logarithm of the solute retention factor, $k^{\prime}=\left[t_{r}-t_{0}\right] / t_{0},\left(t_{r}\right.$ and $t_{o}$ being the solute retention time and the dead time, respectively) in an ODS column obtained for each mobile phase composition was extrapolated to pure water (by using equation 2) to obtain the lipophilic descriptor log $k^{\prime}{ }_{w}$. We used equation 2 since no linearity was observed with equation 1 for most of the compounds. The relative standard deviations for three replicates of k' were, in each instance, fairly low (under $0.5 \%$ ). The regression equation parameters (equation 2) are reported in Table 2.

Table 2: Retention model parameters from equation 2 for the studied $N$-oxide derivatives.

\begin{tabular}{ccccc}
\hline Compound & log $\mathrm{k}_{\mathrm{w}}{ }_{\mathrm{w}}$ & $-\mathrm{a}$ & $\mathrm{b}$ & $\mathrm{r}^{2, \mathrm{a}}$ \\
\hline $\mathbf{1}^{\mathbf{c}}$ & - & - & - & - \\
$\mathbf{2}$ & 3.34 & 25.1 & 0.45 & 0.9992 \\
$\mathbf{3}$ & 3.24 & 25.2 & 0.45 & 0.9996 \\
$\mathbf{4}$ & 4.24 & 29.1 & 0.53 & 0.9932 \\
$\mathbf{5}^{\mathbf{c}}$ & - & - & - & - \\
$\mathbf{6}$ & 0.22 & 8.5 & 0.14 & 0.9722 \\
$\mathbf{7}$ & 1.47 & 13.5 & 0.24 & 0.9956 \\
$\mathbf{8}$ & 4.39 & 31.8 & 0.57 & 0.9914 \\
$\mathbf{9}$ & 1.18 & 11.9 & 0.21 & 0.9954 \\
$\mathbf{1 0}$ & 2.18 & 13.5 & 0.25 & 0.9920 \\
$\mathbf{1 1}$ & 2.40 & 19.1 & 0.34 & 0.9565 \\
$\mathbf{1 2}$ & - & - & - & - \\
$\mathbf{1 3}$ & 2.02 & 16.7 & 0.29 & 0.9980 \\
$\mathbf{1 4}$ & 2.31 & 21.1 & 0.37 & 0.9978 \\
$\mathbf{1 5}$ & 1.46 & 15.6 & 0.27 & 0.9972 \\
$\mathbf{1 6}$ & 1.27 & 10.3 & 0.18 & 0.9851 \\
$\mathbf{1 7}$ & 2.74 & 18.47 & 0.34 & 0.9958 \\
$\mathbf{1 8}$ & - & - & - & - \\
$\mathbf{1 9}$ & 2.21 & 19.2 & 0.34 & 0.9864 \\
\hline${ }^{\mathbf{c}}$ Square regression coefficient; ${ }^{\mathrm{b}}$ & Appropriate elution \\
was not possible for the whole range & & &
\end{tabular}

According to structural and polarity distribution analogies between a typical solvated HPLC reverse phase and the octanol-water system, it is expected for the theoretically calculated $\log \mathrm{P}_{\mathrm{o} / \mathrm{w}}$ parameter to be linearly related to the partition chromatographic parameter, $\log \mathrm{k}_{\mathrm{w}}^{\prime}$ (equation 3) [23].

$$
\log \mathrm{P}_{\mathrm{o} / \mathrm{w}}=\mathrm{m} \log \mathrm{k}_{\mathrm{w}}^{\prime}+\mathrm{n}
$$

where, $\mathrm{m}$ and $\mathrm{n}$ are the regression constants. 
In Figure 1 the extrapolated $\log \mathrm{k}_{\mathrm{w}}$ for the ODS column are plotted against the calculated $\log \mathrm{P}_{\mathrm{o} / \mathrm{w}}$ data. A fair correlation (equation 4$)$ is obtained:

$$
\begin{array}{r}
\log \mathrm{k}_{\mathrm{w}}^{\prime}=(1.3 \pm 0.2) \log \mathrm{P}_{\mathrm{o} / \mathrm{w}}-(2.0 \pm 0.6) \\
\mathrm{r}^{2}=0.8491 \quad \mathrm{n}=11
\end{array}
$$

Figure 1: Relationship between $\log \mathrm{k}_{\mathrm{w}}{ }_{\mathrm{w}}$ and $\log \mathrm{P}_{\mathrm{o} / \mathrm{w}}$ for ODS column.

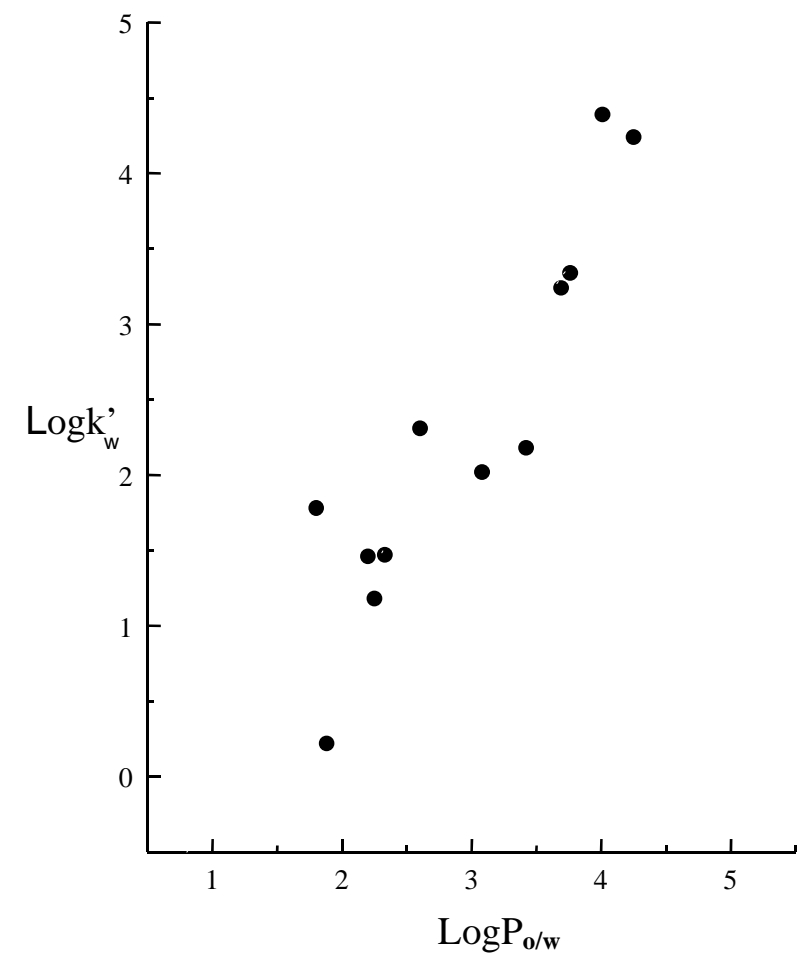

Thus, considering the approximations of the calculated $\log \mathrm{P}_{\mathrm{o} / \mathrm{w}}$ data and assuming that this parameter as mostly reflecting hydrophobic interactions (as in an octanol-water partition system), the obtained linear regression means that the molecular interactions between these $N$-oxide derivatives and the ODS column are mainly of hydrophobic nature. Consequently, both descriptors can be used alternatively to model lipophilic interactions.

\section{Cyclic Voltammetry and ESR}

Table 1 lists the values of the first cathodic peaks, the reduction potentials, $\mathrm{E}_{\mathrm{r}}$, obtained by cyclic voltammetry. These compounds displayed comparable voltammetric behaviour, showing one, two or three well-defined reduction waves both in DMSO and in DMF. The first wave corresponds to a quasireversible process that could be assigned to the following process:

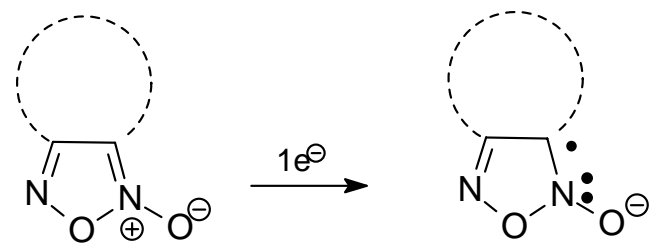


To confirm the free radical production in the first wave we performed ESR spectroscopy. Thus, the $\mathrm{N}$-oxide free radicals were prepared in situ by electrochemical reductions in DMSO, applying a potential corresponding to the first wave for the $\mathrm{N}$-oxides as obtained from the cyclic voltammetric experiments. The interpretation of the ESR spectra by means of a simulation process led to the determination of the coupling constants for all the magnetic nuclei, confirmed by theoretical calculations. [26] In Figure 2 the ESR spectrum of compound $\mathbf{1 8}$ is shown as an example. In this case, two triplets could be assigned to the two nitrogen atoms of the oxadiazole system $\left(\mathrm{a}_{\mathrm{N} 1}=7.10 \mathrm{G}\right.$; $\mathrm{a}_{\mathrm{N} 2}=$ $2.50 \mathrm{G})$ and one triplet was accounted for two aromatic ring hydrogen atoms $\left(\mathrm{a}_{\mathrm{H}}=0.70 \mathrm{G}\right)$.

Figure 2: ESR spectra of compound 18 in DMSO.

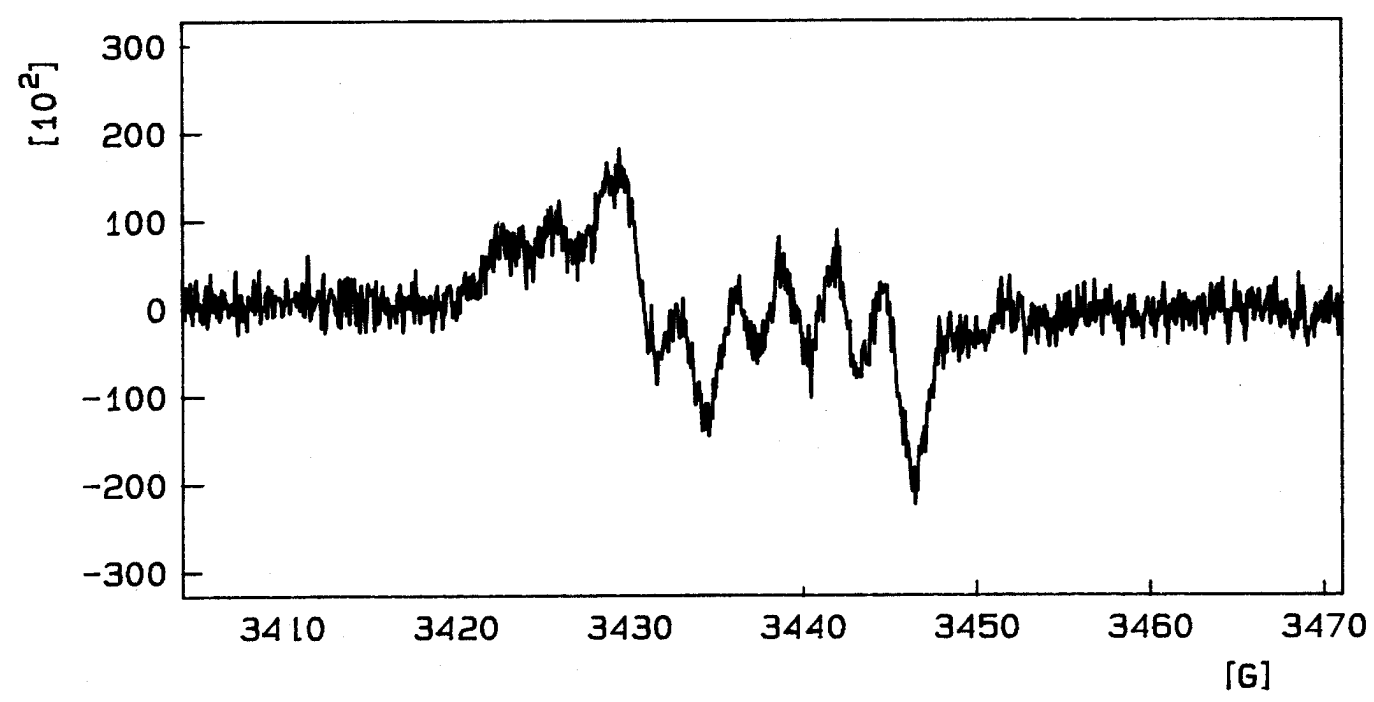

Calculation of quantum-chemical descriptors

The calculation of the quantum-chemical descriptors $\mu$, and $\mathrm{q}_{0}$, for the different compounds were performed using a semiempirical molecular orbital method (AM1) [31], starting from standard bond lengths and bond angles. All geometries were fully optimised by minimising the energy with respect to geometrical variables without symmetry constraints, using a $0.01 \mathrm{Kcal} / \mathrm{mol}$ gradient and the PolakRibierie algorithm as convergence criteria. The $\log \mathrm{P}_{\mathrm{o} / \mathrm{w}}$ and $\mathrm{V}$ values were calculated by using the ChemPlus extension.

Complexes of pyridine $N$-oxides with some acids are used in agriculture to regulate plant growth rates. In order to analyse the mechanism of this biological activity in [18] the structural and electronic characteristic of the hydrogen bonding interaction between pyridine derivatives and phenols by experimental and semiempirical methods (AM1 and PM3) was studied. They concluded that the proton acceptor ability of pyridine $\mathrm{N}$-oxide derivatives correlates with the charge $\left(\mathrm{q}_{\mathrm{o}}\right.$ ) on the oxygen atom of the $\mathrm{N} \rightarrow \mathrm{O}$ group. Changes in the charge of the oxygen atom are reflected in the equilibrium constant of complex formation. In the present work, qo was utilized as hydrogen bond acceptor ability index.

In the oxadiazole derivatives (compounds 1-9) the different functionalities are included in the same cycle than the $\mathrm{N} \rightarrow \mathrm{O}$. Consequently, the changes observed in the Mulliken's charge $\left(\mathrm{q}_{\mathrm{o}}\right)$ on the oxygen atom of the $\mathrm{N} \rightarrow \mathrm{O}$ group for different functionalities, are more significant than in the benzo-oxadiazole derivatives (compounds 10-18, Table 1). 
Contributing factors to the biological response

The choice of the descriptors utilized in this work is based in previous studies that have shown that electronic effects and lipophilic-hydrophilic balance of the compounds may explain some differences in biological activity [24]. As multilinearity diagnostic the correlation matrix for the used physicochemical properties descriptors was performed (Table 3). The values obtained indicate a small cross-correlation between most of the descriptors, except to $\log ^{\prime}{ }_{\mathrm{w}}$ and $\mathrm{V}$. The analysis of the correlation matrix allowed one to safely use these factors in the multi-parameter regression [24]. However, calculated $\log \mathrm{P}_{\mathrm{o} / \mathrm{w}}$ and $\mathrm{q}_{\mathrm{o}}$ show certain correlation when they are analyzed by family of compounds ( $r^{2}=0.924$ for compounds $1-5$ and $r^{2}=0.775$ for compounds $10-18$ ) such was described by [19].

Table 3: Correlation matrix for the used physicochemical descriptors

\begin{tabular}{|c|c|c|c|c|c|c|}
\cline { 2 - 7 } \multicolumn{1}{c|}{} & $\mathbf{E}_{\mathbf{r}}$ & $\log _{\mathbf{w}}$ & $\log _{\mathbf{0}} \mathbf{w}$ & $\mathbf{V}$ & $\boldsymbol{\mu}$ & $\mathbf{q}_{\mathbf{o}}$ \\
\hline $\mathbf{E}_{\mathbf{r}}$ & 1 & 0.25 & 0.03 & 0.02 & 0.05 & 0.01 \\
$\mathbf{L o g k}_{\mathbf{w}}$ & - & 1 & 0.92 (4 outliers) & 0.78 & 0.37 & 0.02 \\
$\log _{\mathbf{0} / \mathbf{w}}$ & - & - & 1 & 0.13 & 0.01 & 0.23 \\
$\mathbf{V}$ & - & - & - & 1 & 0.29 & 0.13 \\
$\boldsymbol{\mu}$ & - & - & - & - & 1 & 0.17 \\
$\mathbf{q}_{\mathbf{o}}$ & - & - & - & - & - & 1 \\
\hline
\end{tabular}

Multi-parameter regressions between the different herbicide bioactivity indexes and the calculated and experimental descriptors were performed. The adjust regression coefficient (AdjR-squared) has been utilized as evaluation criteria of the regression sub-models. The regression model quality has been validated in function of the analysis of residuals. The best results are summarized in Table 4. No good regressions were obtained with the calculated quantum-chemical parameters $\mathrm{V}, \mathrm{q}_{\mathrm{o}}$, and $\mu$.

Table 4 : Multi-parameter regressions between the biological indexes and physicochemical properties of $\mathrm{N}$-oxide derivatives

\begin{tabular}{|c|c|c|c|c|c|}
\hline $\mathbf{N}^{\circ}$ & Multi-parameter regression & $\begin{array}{c}\text { R- } \\
\text { squared }\end{array}$ & $\begin{array}{l}\text { Adj-R- } \\
\text { squared }\end{array}$ & Prob $>$ F & $\mathbf{n}^{\mathbf{b}}$ \\
\hline $\mathbf{I}$ & $\boldsymbol{a} \boldsymbol{w}=(167 \pm 26)+(95 \pm 12) \mathrm{E}_{\mathrm{r}}-(18 \pm 3) \log \mathrm{k}_{\mathrm{w}}$ & 0.8866 & 0.8542 & 0.005 & 10 \\
\hline II & $\boldsymbol{a} \boldsymbol{w}=(132 \pm 24)+(66 \pm 10) \mathrm{E}_{\mathrm{r}}-(15 \pm 3) \log \mathrm{P}_{\mathrm{o} / \mathrm{w}}$ & 0.7490 & 0.7074 & 0.0005 & 13 \\
\hline III & $\boldsymbol{I} \boldsymbol{f l}=(78 \pm 20)+(56 \pm 9) \mathrm{E}_{\mathrm{r}}-(9 \pm 3) \log \mathrm{k}_{\mathrm{w}}$ & 0.8270 & 0.7780 & 0.002 & 10 \\
\hline IV & $\boldsymbol{I} \boldsymbol{f} \boldsymbol{l}=(74 \pm 17)+(48 \pm 9) \mathrm{E}_{\mathrm{r}}-(8 \pm 2) \log \mathrm{P}_{\mathrm{o} / \mathrm{w}}$ & 0.8445 & 0.8000 & 0.0015 & 10 \\
\hline
\end{tabular}


However, acceptable regression was obtained with the experimental descriptors $E_{\mathrm{r}}$ and $\log \mathrm{k}_{\mathrm{w}}$, and the $\boldsymbol{a} \boldsymbol{w}$ biological index. (Table 4, I). The use of the calculated lipophilic descriptor $\log \mathrm{P}_{\mathrm{o} / \mathrm{w}}$ values for correlation (Table 4, II) yield comparable results that as in I. That demonstrates than $\log \mathrm{k}_{{ }_{\mathrm{w}}}$ and $\log$ $\mathrm{P}_{\mathrm{o} / \mathrm{w}}$ descriptors can be used alternatively for these compounds to model lipophilic interactions.

There are similar correlations between physicochemical descriptors and both $\boldsymbol{a w}$ (Table 4, I and II) and $\boldsymbol{I} \boldsymbol{f l}$ biological indexes (Table 4, III and IV). These results are not surprising since $\boldsymbol{a} \boldsymbol{w}$ and $\boldsymbol{I} \boldsymbol{f} \boldsymbol{l}$ are related parameters as is shown in the correlation matrix given in Table 5.

Table 5: The correlation matrix between herbicidal activity indexes of 1,2,5-oxadiazole $N$-oxide derivatives.

\begin{tabular}{|c|c|c|c|}
\cline { 2 - 4 } \multicolumn{1}{c|}{} & rw & aw & lfl \\
\hline rw & 1 & 0.19 & 0.13 \\
aw & - & 1 & 0.67 \\
lfl & - & - & 1 \\
\hline
\end{tabular}

On the other hand, very poor correlations were obtained with the $\boldsymbol{r} w$ index. Other physicochemical descriptors could be related to the oxadiazole's effects over radicular weight, presumably because the mechanism of action at this level is different from that who affects the aerial parts of the plant.

Also, a relevant relationship was observed between the variance in the biological activity produced by changes in the different functionalities of the $N$-oxide derivatives and both the reduction potential and lipophilicity (Table 4). We propose that the interaction between the drug and the receptor is electronic in nature, where the $N$-oxide moiety participates in the redox process, but also it depends on the hydrophobic balance of the compounds.

\section{Conclusions}

The results obtained show that $\log \mathrm{k}_{\mathrm{w}}$ and $\log \mathrm{P}_{\mathrm{o} / \mathrm{w}}$ descriptors can be used alternatively to model lipophilic interactions for the $N$-oxide series studied. An irrelevant relationship was observed between the variance in the biological activity produced by changes in the different functionalities in the $N$ oxide derivatives and the proton acceptor ability, measured by the Mülliken's charge on the oxygen atom of the N-oxide $\left(\mathrm{q}_{\mathrm{o}}\right)$, probably due to the small variation observed in this descriptor for the studied compounds. The obtained physicochemical descriptors $E_{r}$ and $\log \mathrm{k}^{\prime}{ }_{\mathrm{w}}$ allow a qualitative, reasonable explanation for the bioactivity data of these $N$-oxide derivatives with a variegated set of substituents.

\section{Acknowledgments}

Financial support from the Consejo Nacional de Investigaciones Científicas y Técnicas (CONICET-Argentina), Consejo de Investigaciones Científicas y Tecnológicas de la Provincia de Córdoba (CONICOR-Argentina), Agencia Nacional de Promoción Científica y Tecnológica (FONCYT-Argentina), Secretaría de Ciencia y Técnica de la Universidad Nacional de Río Cuarto (SECYT-UNRC). Collaborative work was performed under the auspices of the Iberoamerican Program 
for Science and Technology (CYTED), SubProgram X, network X-E, RIIDDMED. M. Risso thanks to the RELAQ for the fellowship.

\section{Experimental}

\section{General}

The 1,2,5-oxadiazole $\mathrm{N}$-oxide derivatives studied, summarized in Scheme 1 , were prepared as described previously [17]. Acetonitrile (ACN) was HPLC grade from Sintorgan and used as received except for the chromatographic measurements for which was filtered through a Nylon 66, $0.45 \mu \mathrm{m}$ membrane. For the spectroscopic studies, the UV cut-off point in $10 \mathrm{~mm}$ cell against air was used as purity criteria [25]. Ultra-pure water was obtained using LABCONCO model 90901-01 equipment and then filtered through a cellulose nitrate $0.45 \mu \mathrm{m}$ filter (MSF). A Varian Model 5000 liquid chromatograph with manual loop injector connected to a model $2550 \mathrm{UV}$-visible detector and to a Varian 4270/4290 integrator was used for liquid chromatography. A Micropack MCH-10 column, 150 x $0.46 \mathrm{~mm}$ i.d. (ODS) thermostated at $25^{\circ} \mathrm{C}$ was used. The dead time $\left(\mathrm{t}_{0}\right)$ was measured using an aqueous solution of $\mathrm{NaNO}_{2}$ at $210 \mathrm{~nm}$. The UV-visible spectroscopic measurements were made in a Shimadzu UV 2401 PC spectrophotometer thermostated cells. For cyclic voltammetry studies, dimethylsulfoxide (DMSO) and dimethylformamide (DMF) (spectroscopy grade) were obtained from Aldrich. Tetrabutylammonium perchlorate (TBAP) used as supporting electrolyte was obtained from Fluka. Cyclic voltammetry was carried out using a Weenking POS 88 instrument with a Kipp Zonen BD93 recorder, in DMSO or DMF ( ca $1.0 \times 10^{-3} \mathrm{~mol} \mathrm{dm}^{-3}$ ), under a nitrogen atmosphere, with TBAP (ca. $0.1 \mathrm{~mol} \mathrm{dm}^{-3}$ ), using three-electrode cells. A mercury-dropping electrode was used as the working electrode, a platinum wire as the auxiliary electrode, and saturated calomel as the reference electrode [26]. To analyze the products obtained in the cyclic voltammetry first waves (one electro reduction product), electron spin resonance (ESR) spectroscopy was employed [27,28]. The $N$-oxide radicals were generated by in situ electrolytic reduction at $25^{\circ} \mathrm{C}$ and the ESR spectra were recorded in the $\mathrm{X}$ band $(9.85 \mathrm{GHz})$ using a Bruker ECS 106 spectrometer with a rectangular cavity and $50 \mathrm{KHz}$ field modulation. The hyperfine splitting constants were estimated to be accurate within $0.05 \mathrm{G}$ [29,30]. The quantum chemical descriptors (dipolar moment, $\mu$, and the Mulliken's charge $\left(\mathrm{q}_{\mathrm{o}}\right)$ on the oxygen atom of the $\mathrm{N} \rightarrow \mathrm{O}$ group of the $\mathrm{N}$-oxide derivatives) were calculated by semiempirical molecular orbital methods AM1 [31] using the HyperChem software, version 5.0. The $\log \mathrm{P}_{\mathrm{o} / \mathrm{w}}$, and $\mathrm{V}$ values were calculated by using the ChemPlus module of HyperChem 5.0. The biological activity, evaluated in pre-emergence herbicide assays, was expressed as the decrease in the following parameters: length of first leaf (lfl), aerial weight (aw), radicular weight (rw), compared with an untreated control. The herbicide evaluation was described in detail in reference [17].

\section{References}

1 Wermuth, C.G., Ed. “The Practice of Medicinal Chemistry”; Academic Press: New York, 1996.

2 Basak, S.C.; Niemi G.J.; Veith, G.D. Optimal characterization of structure for prediction of properties. J. Math. Chem. 1990, 4, 185-202. 
3 Basak, S.B.; Monsrud, L.J.; Rosen, M.E.; Frane, C.M.; V.R. Magnuson. A comparative study lipophlicity and topological indices in biological correlation. Acta Pharm. Jugosl. 1986, 36, 8195.

4 Santo, M; Giacomelli, L.; Reta, M.; Cattana, R.; Silber, J.; Chana, A.; Rodriguez, M.; Ochoa, C. Role of weak molecular interaction in the mechanism of action a serie of antihelmintcs. Molecules. 2000, 5, 317-378.

5 Aguirre, G.; Cerecetto, H.; Di Maio, R.; Gonzalez, M.; Porcal, W.; Seoane, G.; Ortega, M.A.; Aldana, I.; Monge, A.; Denicola, A. Benzo[1,2-c]1,2,5-oxadiazole N-oxide derivatives as potential antitrypanosomal drugs. Structure-activity relationships. Part II. Arch. Pharm. Med. Chem. 2002, 335, 15-21.

6 Manhold, R.; Kubinyi, H.; Timmerman, H. "Lipophilicity in Drug Action and Toxicology”; In "Methods and Principles in Medicinal Chemistry"; Pilska, V.; Testa, B; Van de Waterbeemd, H. Eds.; VCH: Weinheim, New York, 1996; Vol. 4;.

7 Hadjipavlou-Litina, D.; Hantzch, C. Quantitative Structure-Activity Relationships of the Benzodiazepines. A Review and Reevaluation. Chem. Rev. 1994, 91, 1483-1505.

8 Hsieh, M. M.; Dorsey, J.G. Accurate determination of $\log \mathrm{k}^{\prime} \mathrm{w}$ in reversed-phase liquid chromatography. Implications for quantitative structure-retention relationships. J. Chromatogr. 1993, 631, 63-78.

9 Ghose, A.; Crippen, G. Atomic physicochemical parameters for three-dimensional-structuredirected quantitative structure-activity relationships. 2. Modeling dispersive and hydrophobic interactions. J. Chem. Inf. Comput. Sci. 1987, 27, 21-35.

10 Michels, J.J.; Dorsey, J.G. Estimation of the reversed-phase liquid chromatographic lipophilicity parameter log k'w using ET-30 solvatochromism. J. Chromatogr. 1990, 499, 435-451.

11 Dorsey, J.; Khaledi, M. Hydrophobicity estimations by reversed-phase liquid chromatography. $J$. Chromatogr. A 1993, 656, 485-499.

12 Lambert, W.J. Modeling oil-water partitioning and membrane permeation using reversed-phase chromatography. J. Chromatogr. A 1993, 656, 469-.484.

13 Gancia, E.; Montana, J.G.; Manallack, D.T. Theoretical hydrogen bonding parameters for drug design. J. Mol. Graph. Model. 2001, 19, 349-362.

14 Katritzky, A.R.; Lobanov, V.S. ; Karelson, M. QSPR: Correlation and Quantitative Prediction of Chemical and Physical Properties from Structure. Chem. Soc. Rev. 1995, 279-287.

15 Monge, A.; Palop, J.A.; Lopez de Cerain, A.; Senador, V.; J.Martinez-Crespo, F.; Sainz, Y.; Narro, S.; Garcia, E.; Gonzalez, M.; Hamilton, E.; Barker, A. J.; Clarke, E. D.; Greenhow, D. T. Hypoxia-Selective Agents Derived from Quinoxaline 1,4-Di-N-oxides. J. Med. Chem. 1995, 38, 1786-1792.

16 Cerecetto, H.; Gonzalez, M. N-Oxides as hypoxia selective cytotoxins. Mini Rev. Med. Chem. 2001, 1, 219-231.

17 Cerecetto, H.; Dias, E.; Di Maio, R.; González, M.; Pacce, S.; Saenz, P.; Seoane, G.; Suescun, L.; Mombrú, A.; Fernández, G.; Lema, M.; Villalba, J. Synthesis and Herbicidal Activity of NOxide Derivatives. J. Agric. Food Chem. 2000, 48, 2995- 3002. 
18 Prezhdo, V.V.; Vasshchenko, E.V. ; Prezhdo, O.V.; Pushko, A. Structure and properties of hydrogen bonded complexes of pyridine-N-oxide and its derivatives J. Mol. Struc. 1999, 510, 6983.

19 Caron, G.; Carrupt, P.A.; Testa, B.; Ermondi, G.; Gasco, A. Insight into the lipophilicity of the aromatic N-oxide moiety Pharm. Res. 1996, 13, 1186-1190.

20 Valkó, K.; Snyder, L.R.; Glajch, J.L. Retention in reversed-phase liquid chromatography as a function of mobile-phase composition., J. Chromatogr. 1993, 656, 501-520.

21 Kaliszan, R. "Structure and Retention in Chromatography. A Chemometric Approach"; Harwood Academic Publishers: London, 1997; pp. 155-203.

22 Hsieh, M.M.; Dorsey, J.G. Bioavailability estimation by reversed-phase liquid chromatography: high bonding density C-18 phases for modeling biopartitioning processes. Anal. Chem. 1995, 67, 48-57.

23 Brown, P.R.; Hartwick, R.A., Eds. "High Performance Liquid Chromatography”; J. Wiley \& Sons: New York, 1989.

24 Myers, R. H., Ed. “Classical and Modern Regression with Applications”; P.W.S. Publishers: Boston, 1986.

25 Riddick, J.A.; Bunger, W.B. Eds. “Techniques of Chemistry” $3^{\text {rd }}$ Ed.; Wiley-Interscience: New York, 1970.

26 Olea-Azar, C.; Rigol, C.; Mendizabal, F.; Briones, R.; Cerecetto, H. ; Di Maio, R.; Gonzalez, M.; Porcal, W. ; Risso, M. . Electrochemical and microsomal production of free radicals from 1,2,5-oxadiazole N-oxide as potential antiprotozoal drugs. Spectrochim. Acta 2003, 59A, 69-75.

27 Cerecetto, H.; Di Maio, R.; Gonzalez, M.; Risso, M.; Saenz, P.; Seoane, G.; Denicola, A.; Peluffo,G.; Quijano, C.; Olea-Azar, C.1,2,5-Oxadiazole N-Oxide Derivatives and Related Compounds as Potential Antitrypanosomal Drugs: Structure-Activity Relationships. J. Med. Chem. 1999, 42, 1941-1950.

28 Monge, A.; Lopez de Cerain, A. ; Ezpeleta, O.; Cerecetto, H.; Dias, E.; Di Maio, R.; Gonzalez, M.; Onetto, S.; Risso, M.; Seoane, G.; Zinola, F; Olea-Azar, C. 1,2,5-Oxadiazole N-Oxide Derivatives as Hypoxia-Selective Cytotoxins. Structure-Activity Relationships. Die Pharmazie 1998, 53, 698-702.

29 Olea-Azar, C.; Atria, A. M.; Di Maio, R.; Seaone, G.; Cerecetto, H. Electron Spin Resonance and Cyclic Voltammetry Studies of Nitrofurane and Nitrothiophene Analogues of Nifurtimox. Spectrosc. Lett. 1998, 31, 849-857.

30 Olea-Azar, C.; Atria, A. M.; Mendizabal, F.; Di Maio, R.; Seoane, G.; Cerecetto, H. Cyclic Voltammetry and Electron Paramagnetic Resonance Studies of Some Analogues of Nifurtimox. Spectrosc. Lett. 1998, 31, 99-109.

31 Dewar, M.J.S.; Zoebisch, E.G.; Healy, A.F.; Stewart, J.J.P. AM1: A New General Purpose Quantum Mechanical Molecular Model. J. Amer. Chem. Soc. 1985, 107, 3902-3909.

Sample availability: Not Applicable

(C) 2005 by MDPI (http:www.mdpi.org). Reproduction is permitted for noncommercial purposes 